\title{
SOB A PERSPECTIVA DO CONTRATO: UMA ANÁLISE ECONÔMICA DO DIREITO A PARTIR DA LEI DA LIBERDADE ECONÔMICA
}

\section{ARTIGO ORIGINAL}

MACÊDO, Karen Vanderlei ${ }^{1}$

MACÊDO, Karen Vanderlei. Sob a perspectiva do contrato: Uma análise econômica do direito a partir da Lei da Liberdade Econômica. Revista Científica Multidisciplinar Núcleo do Conhecimento. Ano 05, Ed. 12, Vol. 18, pp. 22-28. Dezembro de 2020. ISSN: 2448-0959, Link de acesso: https://www.nucleodoconhecimento.com.br/lei/perspectiva-do-contrato

\section{RESUMO}

O artigo trata da mudança dos princípios que regem os contratos na legislação brasileira, assim como os fatores que a fizeram utilizar em suas interpretações a Análise Econômica do Direito. Com a ideologia progressista, o protagonismo político do Supremo Tribunal Federal, a "supremocracia" e da mudança de governo, o Brasil passou a adotar uma interpretação do contrato em que confere maior liberdade ao mercado e, assim, consecutivamente, reduz o papel do Estado. Por fim, a partir da Lei da Liberdade Econômica de 2019, observa-se, de fato, a presença dos elementos da economia no ordenamento jurídico brasileiro.

Palavras-Chave: Contratos, Análise Econômica do Direito, Lei da Liberdade Econômica.

${ }^{1}$ Graduação em Direito (Estácio CEUT), Especialização em Gestão Pública com ênfase em licitação de contratos (FAR); Especialização em Direito Público (FAR, em andamento) e Mestrado em Direito Público (Universidade Portucalense, em andamento). 


\section{INTRODUÇÃO}

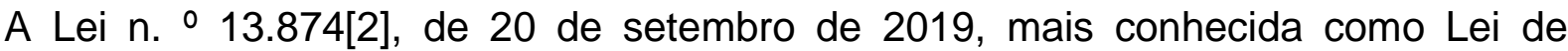
Liberdade Econômica - LEC, institui diversas mudanças no que tange à compreensão legal das relações de contrato. Dentre tais modificações, vislumbram-se várias alterações na Lei n. ${ }^{010.406[3], ~ d e ~} 10$ de janeiro de 2002, o Código Civil brasileiro. As alterações se deram no âmbito da anunciada "Liberdade Econômica", defendida pelo Governo Brasileiro, eleito para o período de 2019 a 2022, em detrimento do que foi preceituado na sua versão inicial, que trazia, enquanto fundamentos, a proteção do bem comum e da função social do contrato.

O pressuposto do presente estudo é que, com a validação da LEC, o contrato brasileiro pode a vir tomar outras feições, em particular, embasadas na Análise Econômica do Direito - AED. A AED, no seu princípio, teve os seus estudos pioneiros na University of Yale e é bastante trabalhada na Faculdade de Direito da University of Chicago (ACCIARRI, 2014), na qual o principal mandatário do governo, quanto à economia, concluiu os seus estudos e se classifica enquanto um Chicago boy.

É imprescindível ressaltar que uma determinada mudança jurídica, faz-se, antes de sua positivação, desde uma escolha política, isto é, o fundamento legal é uma proposição política, um atrelamento às preferências ideológicas dos legisladores que formam um governo. De acordo com Sunstein (2009, p. 228), as ações de um governo quando "culminando na lei, [condizem às] aspirações sociais ou desejos coletivos amplamente sustentados". Essa é uma hipótese que este artigo levanta, ou seja, a mudança que se faz nos fundamentos das relações contratuais se deve a uma modificação de governo, um governo defensor do "livre mercado", o que remonta a uma AED.

Poder-se-ia tentar ver o maior uso do raciocínio econômico em um país latinoamericano como o transplante artificial de modismos acadêmicos estrangeiros que corromperam a coesão e a pureza da tradição do direito civil. Sugerimos que tal suposição é injustificada, pois coloca muito peso no papel das elites intelectuais ao falhar em capturar forças sociais e jurídicas mais amplas em jogo. A hipótese básica 
é que o direito brasileiro contemporâneo - um exemplo típico de uma jurisdição de direito civil - é particularmente passível de raciocínio econômico para (i) fatores ideológicos, (ii) políticos e (iii) legais, relacionados e que se reforçam mutuamente.

Os defensores do "livre mercado" ou da "livre iniciativa" compreendem o mercado

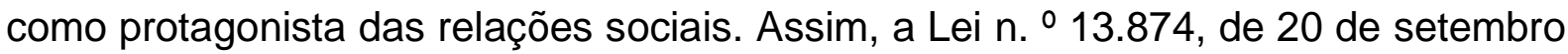
de 2019 confere robustez ao art. 170[4] da Constituição Federal do Brasil promulgada em 1988, que preceitua: "a ordem econômica, fundada na valorização do trabalho humano e na livre iniciativa, tem por fim assegurar a todos existência digna, conforme os ditames da justiça social [...]" (BRASIL, 2019). Em particular, quando a lei da "Liberdade Econômica" adiciona um "Parágrafo Único" ao mencionado artigo, que diz: "É assegurado a todos o livre exercício de qualquer atividade econômica, independentemente de autorização de órgãos públicos, salvo nos casos previstos em lei."

Dessa forma, este estudo se faz com o intuito de compreender a adoção do fundamento do contrato a partir da Lei $\mathrm{n} . \mathbf{0} 13.874$, de 20 de setembro de 2019, em particular, observar a relação da sua concepção com a mudança governamental que ocorreu no Brasil por meio das eleições de 2018. Parte-se da AED como uma forma de balizar as relações sociais, com base nos estatutos legais, especialmente, do instituto do contrato.

Em um primeiro momento será abordada a concepção da ideologia que sustenta a inserção do raciocínio econômico no ordenamento jurídico dos contratos no Brasil. Em segundo lugar, a análise política que corrobora a interpretação econômica no/do ordenamento jurídico do Brasil e, por fim, uma Análise Econômica do Direito, em particular, a partir de uma análise da Lei n. ${ }^{\circ}$ 13.874, de 20 de setembro de 2019.

\section{A JUSTIFICATIVA IDEOLÓGICA}

O primeiro fator eleito é a crescente demanda por raciocínio econômico e a ascensão da ideologia progressista como base do Estado brasileiro moderno. O progressivismo, aqui vagamente entendido como a antítese do conservadorismo, é a ideologia do 
progresso e desenvolvimento, que se baseia em uma forte crença na capacidade humana de alterar deliberadamente a realidade e melhorar a condição humana. No Brasil, a ascensão ao poder do presidente Getúlio Vargas, no início dos anos de 1930, marcou o triunfo do progressivismo como a ideologia dominante do Estado, que recorre ao "uso instrumental da lei" como uma ferramenta para a "engenharia social".

O Estado que abraça a missão de ordenar e aperfeiçoar ativamente a sociedade, em suma, o Estado progressivo, é a encarnação institucional da ideologia progressista. A Constituição brasileira de 1988 está longe de ser tímida quanto às suas ambições progressistas. O Artigo 3 articula explicitamente que "garantir o desenvolvimento nacional", "eliminar a pobreza e a marginalização e reduzir as desigualdades sociais e regionais", além de "promover o bem-estar de todos", são "objetivos fundamentais da República Federativa do Brasil” (BRASIL, 2019).

Art. 3.ำ Constituem objetivos fundamentais da República Federativa do Brasil:

I-Construir uma sociedade livre, justa e solidária;

II-Garantir o desenvolvimento nacional;

III-Erradicar a pobreza e a marginalização e reduzir as desigualdades sociais e

regionais;

IV-Promover o bem de todos, sem preconceitos de origem, raça, sexo, cor, idade

e quaisquer outras formas de discriminação (BRASIL, 2019, p. 11).

O Estado progressista do Brasil está significativamente envolvido na busca de uma série de objetivos ou políticas públicas concretas, seja a eliminação do analfabetismo, seja redução da poluição, seja a promoção da industrialização, seja o combate à violência doméstica. A formulação e implementação de políticas públicas, por sua vez, criam a necessidade de adaptar instrumentos e soluções jurídicas aos objetivos de alcançar fins normativos e concretos. Para realizar tal tarefa, as técnicas tradicionais de raciocínio jurídico, baseadas em gramática, história, lógica e coerência interna, não 
são mais suficientes. Uma vez que os fins legais são dados, o debate jurídico se volta para a questão dos meios adequados para promover tais fins.

\section{A JUSTIFICATIVA POLÍTICA}

A crescente demanda de advogados e juízes por teorias do comportamento humano deve-se não apenas à busca generalizada de políticas públicas pelo estado progressista brasileiro, mas também e principalmente ao papel cada vez maior dos tribunais na formulação e implementação de tais políticas. De acordo com Verissímo (2008), desde 1988, o judiciário passou da periferia para o centro do poder político no Brasil. Após a redemocratização, o Supremo Tribunal Federal assumiu o papel de árbitro dos grandes conflitos institucionais e políticos do país, função anteriormente exercida pelas forças armadas. Vieira (2008) apropriadamente denominou o regime atual do país como uma "supremocracia". Segundo o autor, (2008, p. 445), "o termo supremocracia refere-se à expansão da autoridade do Supremo em detrimento dos demais poderes".

Conforme Vieira (2008), a tendência mundial de expansão do poder judicial assumiu uma configuração particularmente extrema no Brasil. Os caminhos para a revisão judicial da legislação, que é, sem dúvida, o principal mecanismo de interferência dos tribunais na formulação de políticas, são excepcionalmente amplos. Enquanto a grande maioria das jurisdições adota modos de revisão judicial concentrados ou difusos (ou seja, quando eles não deixam de reconhecer completamente a revisão judicial ex post), a lei brasileira contempla ambas as formas de desafios constitucionais à legislação. Esse sistema híbrido, combinado a uma constituição longa, detalhada e ambiciosa, cria uma enorme margem de manobra para o protagonismo judicial, que transforma o STF em um artefato político.

Essa função, de fato, é cada vez mais explícita. Rompendo com a clássica separação de poderes arquitetada por Montesquieu e as concepções arquetípicas do papel dos tribunais nas jurisdições de direito civil, o STF atualmente possui poderes constitucionais para emitir "declarações vinculativas" (as Súmulas Vinculantes), que devem ser seguidas por tribunais inferiores e outros ramos do governo e escolher seus 
casos com base no que considera ser sua "repercussão geral". A Lei 11.418[5] de 2006 define "repercussão geral" como as "questões relevantes do ponto de vista econômico, político, social e jurídico que transcendem os interesses subjetivos". Não deveria surpreender que, tendo sido solicitado explicitamente pelo legislador a considerar apreços econômicos em suas decisões, o STF o tenha obrigado.

De fato, o STF afirmou expressamente que a correção de um "erro de previsão do legislador" é um fundamento legítimo para a revisão judicial. Mas, novamente, o negócio de previsões fica fora do escopo da empresa essencialmente normativa da lei. Para cumprir essa tarefa, os juízes enfrentam uma escolha entre recorrer ao bom senso ou à experiência pessoal sobre como o mundo funciona ou empregar conhecimentos mais sistemáticos gerados pelas ciências sociais, como a economia.

Soma-se à "supremocracia", que favorece a interpretação dos fatos jurídicos a partir, também, da economia, a eleição no ano de 2018 de um governo que vem gerir o Brasil a partir de 2019, que mostrou, desde a sua campanha eleitoral, um interesse de minimizar o Estado, isto é, delegar ao mercado um maior espaço na política brasileira. De acordo com Paulo Guedes, Ministro da Economia, o novo governo defende privatizações das empresas públicas, delegando tais funções para o mercado.

Para Guedes, a cartilha liberal é o caminho para sair do que identifica como armadilha dirigista, embalada por gastos públicos que cresceram sem controle, tendência que avalia ter sido comum a governos militares e civis, de José Sarney e Fernando Henrique Cardoso a Lula e Dilma Rousseff -todos classificados por ele como socialdemocratas (AYRES, 2018).

De acordo com Sunstein (2009), nesta adição, da escolha política, observa-se que as leis não somente seguem uma influência do STF, mas podem vir a ser uma imagem dos ideais políticos de um determinado governo eleito, a exemplo da Lei da Liberdade Econômica, proposta e aprovada no governo que assumiu em 2019. Porém, tal feito a partir da relação entre Executivo e Legislativo não introduziu a economia com uma ciência que importa na análise jurídica, a exemplo dos contratos, mas foi o judiciário, o STF, enfim, a "supremocracia". 


\section{CONSIDERAÇÕES FINAIS}

O maior papel judicial na formulação de políticas não opera em um vácuo legal. Pelo contrário, sob um sistema que se propõe a defender o Estado de direito, o crescimento do poder do judiciário foi acompanhado por mudanças na estrutura das regras legais. Essas mudanças, por sua vez, criam uma demanda crescente de raciocínio econômico de duas maneiras: a) incorporando diretamente as consequências econômicas ao conteúdo das normas legais, e; b) condicionando a aplicação de um determinado regime jurídico à conveniência de suas consequências.

Os contornos e métodos para a aplicação dos princípios legais também se afastam dos de uma regra legal e canônica. É bem sabido que os princípios legais, ao contrário das regras legais, se tornaram cada vez mais influentes na adjudicação de disputas legais, no Brasil e em outros lugares. Mas as regras e os princípios legais têm uma estrutura marcadamente diferente. Enquanto regras legais são normas que descrevem imediatamente o comportamento. Princípios legais são normas que, em vez de descrever o comportamento, estabelecem um "estado ideal de coisas" (isto é, um objetivo) cuja realização implica a adoção de certos comportamentos. Na definição influente de Robert Alexy (2008), os princípios legais são mandatos de otimização, isto é, normas que direcionam a realização de um valor ou objetivo na maior extensão possível, dadas as restrições legais e factuais existentes.

Dessa forma, para fins da prática contratual legal no Brasil, o princípio que prega os fundamentos, a proteção do bem comum e da função social do contrato, pode ceder lugar a uma legislação, a Lei n. $\stackrel{0}{13.874}$, de 20 de setembro de 2019, que reforça o art. 170 da Constituição Federal do Brasil. Confere aos contratos uma interpretação econômica da realidade e confia aos estatutos legais brasileiros o conceito de eficiência.

A Lei 13.874 , de 20 de setembro de 2019, a partir da noção econômica de eficiência determina que se observem os contratos a partir $\S 2^{\circ}$ do art. 1. da referida lei. Assim, o novo regimento confere maior liberdade ao mercado e confia algumas garantias 
antes de responsabilidade do Estado às organizações mercadológicas, o que diminuem o escopo de proteção dos Direitos Fundamentais.

Existem outros dispositivos legais que conferem uma interpretação econômica do direito, em particular, desde uma visão baseada na eficiência e custo-benefício. Porém, o que se destaca desta lei, para a interpretação dos contratos, é que ela confere maior liberdade para os entes ditos de mercado, diminuindo a atuação e proteção do Estado.

\section{REFERÊNCIAS}

ACCIARRI, Hugo A. Elementos da análise econômica do direito de danos. São Paulo: Revista dos Tribunais, 2014.

ALEXY, Robert. Teoria dos direitos fundamentais. São Paulo: Malheiros Editores, 2008.

AYRES, Marcela. O que pensa Paulo Guedes, o cérebro econômico de Jair Bolsonaro. Revista Exame. Disponível em: O que pensa Paulo Guedes, o cérebro econômico de Jair Bolsonaro | Exame. Acesso em: 10/10/19.

BRASIL. Constituição Federativa do Brasil de 1988. Brasília: Senado Federal, 2019. Disponível em: Constituição da República Federativa do Brasil (senado.leg.br). Acesso em: 01/10/19.

BRASIL. Código Civil brasileiro. 2ed. Brasília: Senado Federal, 2008. Disponpivel em: Código Civil 2 ed.pdf (senado.leg.br). Acesso em: 11/12/20.

SUNSTEIN, Cass, R. Preferências e política. Revista Brasileira de Ciência Política, Brasília, n.1. p.219-254, 2009.

TABAK, Benjamin, M. A análise econômica do direito: proposições legislativas e políticas públicas. Revista de Informação Legislativa, n.502, p.321-345, 2015. 
VERISSIMO, M. P. (2008). A constituição de 1988, vinte anos depois: suprema corte e ativismo judicial" à brasileira". Revista Direito GV, São Paulo, n.4, v.2, p.407-440, 2008.

VIEIRA, O. V. Supremocracia. Revista Direito GV, São Paulo, n.4, v.2, p.441-463, 2008.

\section{APÊNDICE - REFERÊNCIAS DE NOTA DE RODAPÉ}

2. Disponível em: L13874 (planalto.gov.br). Acesso em: 11/12/20.

3. Disponível em: Base Legislação da Presidência da República - Lei oㅡ 10.406 de 10 de janeiro de 2002 (presidencia.gov.br). Acesso em: 11/12/20.

4. Disponível em: CONSTITUIÇÃO DA REPÚBLICA FEDERATIVA DO BRASIL (senado.leg.br). Acesso em 11/12/20.

5. Disponível em: Lei no 11.418 (planalto.gov.br). Acesso em: 11/12/20.

Enviado: Dezembro, 2020.

Aprovado: Dezembro, 2020. 